\title{
Glomerulonephritis disease pattern at Saudi tertiary care center
}

\author{
Khalid I. AlMatham, FASN, FACP, Ali F. AlFayez, MBBS, Raghdah A. AlHarthi, MBBS, Falah S. AlMutairi, MBBS, \\ Fahad S. Alrasheedi, MBBS, Abdulrehman Mustafa, MBBS, Mustafa Ahmed, MD, FACP, Basim A. AlMatouq, MD, FASN, \\ Fadil A. AlRowaie, MD, FASN.
}

$$
\begin{aligned}
& \text { ABSTRACT } \\
& \text { الأهد اف : لتقييم التغيرات في نمط الأمراض الكبيبي للمساعدة }
\end{aligned}
$$

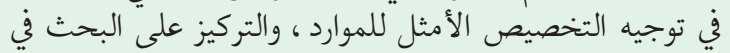

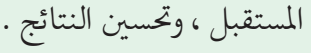

$$
\begin{aligned}
& \text { الطريقة : أجريت مراجعة بأثر رجعي على خزعات الكلى التي }
\end{aligned}
$$

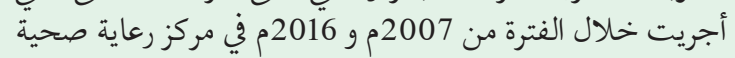

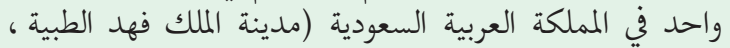

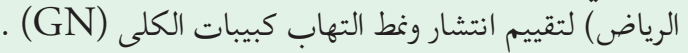

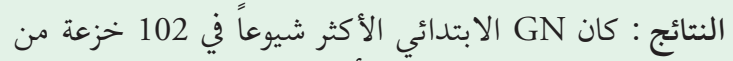

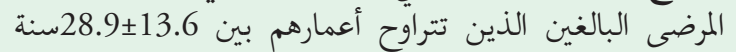

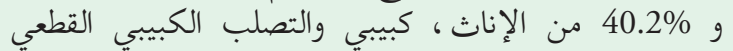

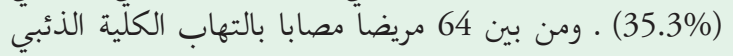

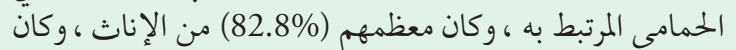

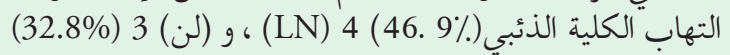

$$
\begin{aligned}
& \text { من الطبقات الأكثر شيوعا لالتهاب الكلية الذئبي . } \\
& \text { الخاتمة : إنشاء سجلات GN المُتملة التي يمكن الخصول عليها }
\end{aligned}
$$

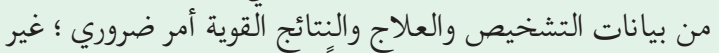

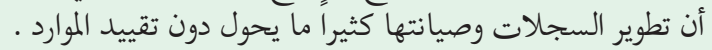

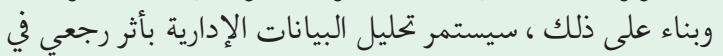

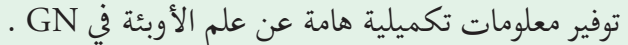

Objective: To assess changes in the pattern of glomerular diseases to help guide optimal allocation of resources, to focus future reasearch, and improve outcomes.

Methods: A retrospective chart review was conducted on kidney biopsies taken between 2007 and 2016 at a single tertiary care center in Saudi Arabia (King Fahad Medical City, Riyadh) to evaluate the prevalence and pattern of glomerulonephritis (GN).

Results: The most common primary GN in 102 biopsies from adult patients with a mean age of $28.9 \pm$
13.6 years and $40.2 \%$ female, was focal and segmental glomerulosclerosis (35.3\%). Among 64 patients with systemic lupus erythematosus associated nephritis, of whom most $(82.8 \%)$ were female, lupus nephritis (LN) 4 (46.9\%), and (LN) $3(32.8 \%)$ were the most common lupus nephritis classes.

Conclusion: Establishing prospective GN registries from which robust diagnosis, treatment, and outcomes data can be acquired is warranted; however, registry development and maintenance are often precluded by resource limitations. Accordingly, retrospective analysis of administrative data will continue to provide important complementary information on GN epidemiology.

Saudi Med J 2017; Vol. 38 (11): 1113-1117 doi: 10.15537/smj.2017.11.21119

From the Department of Medicine (AlFayez, AlHarthi, AlMutairi, Alrasheedi), Nephrology Section (Ahmed, AlMatouq, AlRowaie), King Fahad Medical City, and the AlFaisal University (Mustafa), Riyadh, Kingdom of Saudi Arabia.

Received 9th July 2017. Accepted 16th August 2017.

Address correspondence and reprint request to: Dr. Khalid I. AlMatham, Nephrology Section, Department of Medicine, King Fahad Medical City, Riyadh, Kingdom of Saudi Arabia. E-mail: Kalmatham@kfmc.med.sa

ORCID ID: orcid.org/0000-0002-4383-9442

G lomerulonephritis (GN) is an inflammation of I the capillaries of the glomeruli, characterized by albuminuria, edema, and hypertension. Serious complications of GN include acute renal failure and end stage renal disease (ESRD). Glomerulonephritis is the third leading cause of ESRD in the United States after diabetes and hypertension. ${ }^{1}$ In the Kingdom of Saudi Arabia, GN is the third leading cause of ESRD after diabetes, estimated to be responsible for $3.7 \%$ of 
cases. ${ }^{2}$ Longitudinally reviewing changes in the pattern of glomerular disease prevalence can facilitate designing appropriately focused research on the etiology, pathology, and management strategies across GN types. After a report was published in 2000 describing a series of 782 biopsies acquired at 6 referral hospitals in the Kingdom during an undefined time interval, ${ }^{3}$ a paucity of additional reports became available on the spectrum of GN in the Kingdom. A retrospective analysis of 296 biopsy samples acquired between 1989 to 2007 from adults in the Western region of Saudi Arabia was performed, ${ }^{4}$ and data from single centers in Riyadh representing 120 biopsies performed from 1990 to $2001^{5}$ and 348 biopsies performed from 2005 through 2009 were reported. ${ }^{6}$ To supplement these reports with more recent data, a retrospective review was performed on 166 kidney biopsies performed from 2007 to 2016 at King Fahad Medical City (KFMC), Riyadh, which is a referral center for patients representing all regions of the Kingdom of Saudi Arabia (KSA).

Methods. Native kidney biopsies were obtained from 183 patients at KFMC, Riyadh, KSA, between 2007 and 2016. Biopsies with complete data available, which were obtained from patients with primary GN or with systemic lupus erythematosus (SLE)-associated secondary GN, were included in this review. Additional eligibility included age $\geq 12$ years, which is defined as adult by local authorities. Patients were referred from hospitals throughout the Kingdom or from within KFMC, including the emergency room. Indications for kidney biopsy were proteinuria (nephrotic range or, with SLE >500 mg/day), renal insufficiency, or hematuria.

Biopsies were performed by interventional radiologists under ultrasound guidance, using Tru-Cut biopsy needles. Two to 3 cores of renal tissue were obtained. Sample adequacy was defined as the presence of at least 10 glomeruli, which was confirmed on-site by a pathology lab technician. Samples were processed at KFMC and at the National Guard Hospital, Riyadh, by a nephro pathologist using light microscopy, immunofluorescence, and electron microscopy. Institutional review board approval was obtained before the data were collected.

Data were summarized and means and standard deviations calculated. The Chi-Square and Fisher Exact tests were used to compare proportions, with $p<0.05$ indicating a significant difference between groups.

Results. Of 166 qualifying native kidney biopsies, $102(61.4 \%)$ had primary GN and $64(38.6 \%)$ had SLE-associated GN. In the primary GN cohort, $59.8 \%$ of patients were male and $40.2 \%$ were female, and were an average of $28.9 \pm 13.6$ years at the time of the biopsy (range, 13-70 years). The most common primary glomerular diseases were focal segmental glomerulosclerosis (FSGS; 35.3\%), minimal change disease (MCD; 26.5\%), and membranous nephropathy (MGN; 12.7\%) (Table 1). Female prevalence was 47.2\% in FSGS, $29.6 \%$ in MCD, and 38.5\% in MGN.

Among 64 patients with SLE-associated GN, 17.2\% were male and $82.8 \%$ were female, with an average age of $26 \pm 10.7$ years at the time of the biopsy (range, $14-60$ years). Significantly more SLE GN patients were female compared with the primary GN group $(82.8 \%$ versus $40.2 \%, p<0.0001)$. Lupus nephritis (LN) types were primarily LN4 (46.9\%) and LN3 (32.5\%) (Table 2).

Thirty-one of our patients $(18.7 \%)$ were between 13 and 17 years of age. Excluding these patients, proportions of disease types were slightly different in the resulting subgroup of patients who were $\geq 18$ years of age compared with the type proportions in the entire cohort; however, rank order of type prevalence did not vary between groups (data not shown). For example, among 83 primary GN patients aged $\geq 18$ years, MCD was observed in $21(25.3 \%)$ biopsies, compared with 6 of $19(31.6 \%)$ biopsies of patients aged 13 through 17 years $(p=0.79)$, and $27(26.5 \%)$ biopsies in the entire primary GN cohort of 102 biopsies $(p=0.86)$. Membranous nephropathy was responsible for 12 $(14.5 \%)$ of GN cases in patients $\geq 18$ years, compared with $1(5.3 \%)$ patient aged 13 through $17(p=0.45)$, and $13(12.7 \%)$ patients in the entire primary GN cohort $(p=0.74)$.

Discussion. The prevalence of GN disease states has been shown to vary with time and location worldwide, and the Kingdom is no exception. Several small studies have been reported from the Kingdom with divergent observations. Focal segmental glomerulosclerosis is typically reported as the most common primary GN; however, MCD, MGN, and MPGN have also been reported to have the highest prevalence, although longitudinal data from similar catchment areas are not available. ${ }^{6}$ Registry data were published in 2000 from 4 hospitals in Riyadh, one in Jeddah, and one in the eastern province, which included 782 adult patients with GN. ${ }^{3}$ Similar to our patients, FSGS was also the predominate pattern, observed in $21.3 \%$ of adult biopsies with primary GN. However, it was more prevalent in our patients (35.3\%) compared with that earlier study. A U.S. managed care study reported $38.9 \%$ of $2,501 \mathrm{GN}$ patients $\geq 18$ years of age had FSGS, which increased from a rate of 1.6 per 100,000 person-years in 2000 to 
Table 1 - Primary Glomerulonephritis in 102 Patients: 2007-2016.

\begin{tabular}{|c|c|c|c|c|c|c|}
\hline \multirow[t]{2}{*}{ Variable } & \multicolumn{2}{|c|}{ Male } & \multicolumn{2}{|c|}{ Female } & \multicolumn{2}{|c|}{ Total } \\
\hline & n & $(\%)$ & n & $(\%)$ & $\mathbf{n}$ & $(\%)$ \\
\hline Total & 61 & $(59.8)$ & 41 & $(40.2)$ & 102 & $(100.00)$ \\
\hline Minimal change disease & 19 & $(69.4)$ & 8 & $(29.6)$ & 27 & $(26.5)$ \\
\hline Membranous glomerulonephritis & 8 & $(61.5)$ & 5 & $(38.5)$ & 13 & $(12.7)$ \\
\hline Focal segmental glomerulosclerosis & 19 & $(52.8)$ & 17 & $(47.2)$ & 36 & $(35.3)$ \\
\hline Membranoproliferative glomerulonephritis & 3 & $(50.0)$ & 3 & $(50.0)$ & 6 & $(5.9)$ \\
\hline Immunoglobulin A nephropathy & 7 & $(87.5)$ & 1 & $(12.5)$ & 8 & $(7.8)$ \\
\hline Granulomatosis with polyangiitis & 2 & $(50.0)$ & 2 & $(50.0)$ & 4 & (3.9) \\
\hline Anti-glomerular basement membrane disease & 0 & - & 1 & $(100.0)$ & 1 & $(1.0)$ \\
\hline Post-Infectious glomerulonephritis & 2 & $(50.0)$ & 2 & $(50.0)$ & 4 & $(3.9)$ \\
\hline C1q Disease & 0 & - & 1 & $(100.0)$ & 1 & $(1.0)$ \\
\hline Thrombotic thrombocytopenic purpura & 1 & $(50.5)$ & 1 & $(50.0)$ & 2 & $(2.0)$ \\
\hline \multicolumn{7}{|c|}{$\begin{array}{c}\text { FSGS - focal segmental glomerulosclerosis, IgAN - immunoglobulin A nephropathy, GBMD - glomerular basement } \\
\text { membrane disease, GPA - granulomatosis with polyangiitis, MCD - minimal change disease, MGN - membranous } \\
\text { glomerulonephritis, MPGN - membranoproliferative glomerulonephritis, PIGN - post-infectious glomerulonephritis, } \\
\text { TTP - thrombotic thrombocytopenic purpura }\end{array}$} \\
\hline
\end{tabular}

Table 2 - Systemic lupus erythematosus-associated glomerulonephritis in 64 patients: 2007-2016.

\begin{tabular}{lrlrrrrr}
\hline Variable & \multicolumn{2}{c}{ Male } & \multicolumn{2}{c}{ Female } & \multicolumn{2}{c}{ Total } \\
& $\mathbf{n}$ & $(\%)$ & $\mathbf{n}$ & $(\%)$ & $\mathbf{n}$ & $(\%)$ \\
\hline Total & 11 & $(17.2)$ & 53 & $(82.8)$ & 64 & $(100.0)$ \\
$\begin{array}{l}\text { Lupus nephritis } \\
\text { class 2 }\end{array}$ & 2 & $(18.2)$ & 9 & $(81.8)$ & 11 & $(17.2)$ \\
$\begin{array}{l}\text { Lupus nephritis } \\
\text { class 3 }\end{array}$ & 4 & $(19.0)$ & 17 & $(81.0)$ & 21 & $(32.8)$ \\
$\begin{array}{l}\text { Lupus nephritis } \\
\text { class 4 }\end{array}$ & 5 & $(12.7)$ & 25 & $(83.3)$ & 30 & $(46.9)$ \\
$\begin{array}{l}\text { Lupus nephritis } \\
\text { class 5 }\end{array}$ & - & & 2 & $(100.0)$ & 2 & $(3.1)$ \\
\hline
\end{tabular}

5.3 cases in $2011 .^{7}$ The overall increased GN rates in the 12-year observation interval in the U.S. study were driven by increases in FSGS and also in IgA nephropathy (IgAN), which underwent a 16-fold rate increase from 0.1 in 2000 to 1.6 in 2011 (per 100,000 person years). However, IgAN was only slightly higher in our cohort compared with its prevalence in the earlier KSA registry data $(7.8 \%$ versus $6.5 \%){ }^{3}$ In a study in Western KSA, IgAN was the third most common primary GN, present in $17.6 \%$ of biopsies acquired from 296 adults during the 18-year interval from 1989-2007. ${ }^{4}$ Minimal change disease was represented in $25.3 \%$ of our primary cases $\geq 18$ years of age, which is considerably more than the $11.6 \%$ prevalence reported for the sample included in the KSA registry study published in $2000 .^{3}$ Patients in that study were $30.8 \pm 15.1$ years of age, which is similar to the $28.9 \pm 13.6$ years in our study. Minimal change disease was also considerably less prevalent (11\%) in older patients $(50.6 \pm 16.7)$ comprising the U.S. healthcare system sample of patients aged $\geq 18$ years. $^{7}$

Membranous nephropathy was more common in our sample $(14.5 \%$ in patients $\geq 18$ years) compared with that in the registry data from $2000(10.6 \%))^{3}$ In the Western KSA study, MGN was the most common GN type, noted in $25.7 \%$ of the biopsies. ${ }^{4}$ In the U.S. data, the MGN case rate increased from 0.7 to 1.4 (per 100,000 person years) between 2000 and 2011.

Membranoproliferative glomerulonephritis and MsPGN were identified in biopsies from $20.7 \%$ and $16.3 \%$ of patients in the 2000 KSA registry study; ${ }^{3}$ while MPGN was present in $5.9 \%$ of our patients. Membranoproliferative glomerulonephritis may be less prevalent in our cohort in response to improved control of infections, including hepatitis $\mathrm{C}$ virus.

The $1 \% \mathrm{C} 1 \mathrm{q}$ nephropathy prevalence in our sample, represented by a single patient, is less than the $0.2 \%$ to $2.5 \%$ commonly observed in biopsies from children and adults. ${ }^{8}$ Although C1q nephropathy was proposed as a distinct clinical entity over 30 years ago, its status remains controversial and it continues to be poorly 
understood. ${ }^{9}$ In fact, several reports include FSGS and MCD as subtypes within C1q nephropathy cohorts.

Renal involvement is common in SLE. In a study of 47 women with SLE throughout the Kingdom, renal involvement characterized by proteinuria, hematuria, or nephrotic syndrome was observed in $57.4 \%$ of patients. ${ }^{10}$ In addition, confirmed GN was reported in 27 of 46 patients (58.7\%) from Eastern Saudi Arabia, ${ }^{11}$ and in 299 of 624 (47.9\%) patients diagnosed with SLE from 1980 to 2006 in a tertiary care referral hospital in Riyadh. ${ }^{12}$ Likewise, most studies in the Kingdom have reported LN as the most common cause of secondary GN. ${ }^{6}$ The $38.6 \%$ prevalence of $\mathrm{LN}$ in our entire cohort was much higher than that reported in other series. In the largest study from the Kingdom, reported in 2000, SLE was associated with 126 GN cases; $17.7 \%$ of the cohort comprised primary and LN cases. ${ }^{3}$ In most studies from the Kingdom, LN4 predominates among SLE patients with GN. ${ }^{13}$ Almost half (46.9\%) of our SLE patients had LN4, compared with 37.1\% LN4 prevalence in a cohort of 299 SLE patients with GN reported from a hospital in Riyadh. ${ }^{12,14}$ In that study, only $10 \%$ had LN3 compared with $32.8 \%$ of our patients, while $14.4 \%$ had $\geq \mathrm{LN} 5$, compared with $3.1 \%$ of our SLE patients. Although LN class was not associated with survival in that study, LN3 $(p=0.013)$ and LN4 $(p=0.039)$ were significant risk factors for progression to ESRD.

Determining the pattern of GN is an important aspect of early detection, and epidemiologic study data can promote cost effective screening, and allow focused research efforts on preventing GN and improving patient care across the specific GN forms. Within glomerular diseases, such as LN and IgAN, further classifications using morphologic data have been proposed, in attempts to enhance the ability to provide prognostic information within a diagnosis. ${ }^{15}$ However, the lack of standardization and universal validation of methods for classifying and reporting GN continue to plague these efforts. Several systems have been implemented or proposed, which often are not comprehensive in scope. A consensus meeting endorsed by the Renal Pathology Society was held in 2015, which promoted a pathogenesis-based classification of GN, with guidelines for standardized GN reporting. ${ }^{16}$ However, MGN, MCD, and FSGS were among the glomerular diseases that were not included in the classification system. Data from South Asia and the Middle East are notably lacking in studies of general and specific classifications, ${ }^{17}$ with a single report from Iran exploring the Oxford-MEST IgAN classification in 102 IgAN patients. ${ }^{18}$
In conclusion, our data contribute to documenting and understanding the epidemiology of GN in the Kingdom; however, our study has the inherent weaknesses associated with retrospective studies. Further studies are warranted, with more detailed analysis of disease characteristics, interventions, disease progression and outcomes, and potential prognostic variables. Although there are numerous benefits of a GN registry designed to acquire data prospectively, establishing comprehensive registries is often precluded by resource limitations. Accordingly, retrospective analyses of administrative data, such as that included in this report, can provide an important complementary approach to studying GN epidemiology. ${ }^{19}$

Acknowledgments. We would like to thank Dr. Mohammad AlTannir, Dr. Valerie Zimmerman, and Ms. Carolina Caramat for their support and assistance.

\section{References}

1. USRDS. 2015 USRDS Annual Data Report Volume 2: ESRD in the United States. [Cited 2017 January 1]. Available from: https://www.usrds.org/2015/download/vol2_USRDS_ ESRD_15.pdf

2. SCOT. Saudi Center for Organ Transplantation. 2015 Annual Report. 2015. [Cited 2017 January 1]. Available from: http:// www.scot.gov.sa/Pages/Doc15.aspx?loc=219\&loc2=118

3. Huraib S, Al Khader A, Shaheen FA, Abu Aisha H, Souqiyyeh $\mathrm{MZ}$, Al Mohana F, et al. The spectrum of glomerulonephritis in saudi arabia: the results of the saudi registry. Saudi J Kidney Dis Transpl 2000; 11: 434-441.

4. Jalalah, S. Patterns of primary glomerular diseases among adults in the western region of Saudi Arabia. Saudi J Kidney Dis Transpl 2009; 20: 295-299.

5. Al Wakeel JS, Mitwalli AH, Tarif N, Alam AA, Hammad $\mathrm{D}$, Abu-Aisha $\mathrm{H}$, et al. Spectrum and outcome of primary glomerulonephritis. Saudi J Kidney Dis Transpl 2004; 15: 440-446.

6. Nawaz Z, Mushtaq F, Mousa D, Rehman E, Sulaiman M, Aslam N, et al. Pattern of glomerular disease in the Saudi population: A single-center, five-year retrospective study. Saudi J Kidney Dis Transpl 2013; 24: 1265-1270.

7. Sim JJ, Batech M, Hever A, Harrison TN, Avelar T, Kanter $\mathrm{MH}$, et al. Distribution of biopsy-proven presumed primary glomerulonephropathies in 2000-2011 among a racially and ethnically diverse US population. Am J Kidney Dis 2016; 68: 533-544.

8. Vizjak A, Ferluga D, Rozic M, Hvala A, Lindic J, Levart TK, et al. Pathology, clinical presentations, and outcomes of $\mathrm{C} 1 \mathrm{q}$ nephropathy. J Am Soc Nephrol 2008; 19: 2237-2244.

9. Devasahayam J, Erode-Singaravelu G, Bhat Z, Oliver T, Chandran A, Zeng X, et al. C1q Nephropathy: The Unique Underrecognized Pathological Entity. Anal Cell Pathol (Amst) 2015; 2015: 490413.

10. Albishri J, Alshehri S, Altowairqi A, Aljuaid R. Familial lupus and clinical characteristics in Saudi Arabia. International Journal of Clinical Medicine 2015; 6: 899-905. 
11. Abid N, Khan AS, Al Otaibi FH. Systemic lupus erythematosus (SLE) in the eastern region of Saudi Arabia. A comparative study. Lupus 2013; 22: 1529-1533.

12. Al Arfaj AS, Khalil N, Al Saleh S. Lupus nephritis among 624 cases of systemic lupus erythematosus in Riyadh, Saudi Arabia. Rheumatol Int 2009; 29: 1057-1067.

13. Khan A, Abid N, Khawaja R. Clinical continuum of spstemic lupus in Saudi Arabia. Lupus Open Access 2016; 1: 1000113.

14. Al Arfaj AS, Khalil N. Clinical and immunological manifestations in 624 SLE patients in Saudi Arabia. Lupus 2009; 18: 465-473.

15. Haas M, Rastaldi MP, Fervenza FC. Histologic classification of glomerular diseases: clinicopathologic correlations, limitations exposed by validation studies, and suggestions for modification. Kidney Int 2014; 86: 648.
16. Sethi S, Haas M, Markowitz GS, D’Agati VD, Rennke HG, Jennette JC, et al. Mayo Clinic/Renal Pathology Society Consensus Report on Pathologic Classification, Diagnosis, and Reporting of GN. J Am Soc Nephrol 2016; 27: 1278-1287.

17. Mubarak, M. Oxford classification of IgA nephropathy: Broadening the scope of the classification. J Nephropathol 2012; 1: 13-16.

18. Nasri H, Mortazavi M, Ghorbani A, Shahbazian H, Kheiri S, Baradaran A, et al. Oxford-MEST classification in IgA nephropathy patients: A report from Iran. J Nephropathol 2012; 1: 31-42.

19. O'Shaughnessy MM, Hogan SL. Distinguishing the Signals From the Noise: Can Epidemiologic Studies Inform Our Understanding of Glomerular Disease? Am J Kidney Dis 2016; 68: 503-507.

\section{www.smj.org.sa}

Saudi Medical Journal Online features

* Instructions to Authors

* Uniform Requirements

* STARD

* Free access to the Journal's Current issue

* Future Contents

* Advertising and Subscription Information

All Subscribers have access to full text articles in HTML and PDF format. Abstracts and Editorials are available to all Online Guests free of charge. 